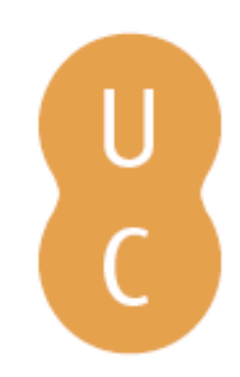

\title{
pompalina
}

\section{A influência da antroposociologia e criminalística na formação intelectual de Mendes Correia}

Autor(es): $\quad$ Oliveira, Alexandre Manuel Teixeira Guedes da Silva

Publicado por: Imprensa da Universidade de Coimbra

URL

persistente: URI:http://hdl.handle.net/10316.2/32339

DOI: $\quad$ DOI:http://dx.doi.org/10.14195/978-989-26-0362-9_19

Accessed : $\quad$ 26-Apr-2023 09:56:02

A navegação consulta e descarregamento dos títulos inseridos nas Bibliotecas Digitais UC Digitalis, UC Pombalina e UC Impactum, pressupõem a aceitação plena e sem reservas dos Termos e Condições de Uso destas Bibliotecas Digitais, disponíveis em https://digitalis.uc.pt/pt-pt/termos.

Conforme exposto nos referidos Termos e Condições de Uso, o descarregamento de títulos de acesso restrito requer uma licença válida de autorização devendo o utilizador aceder ao(s) documento(s) a partir de um endereço de IP da instituição detentora da supramencionada licença.

Ao utilizador é apenas permitido o descarregamento para uso pessoal, pelo que o emprego do(s) título(s) descarregado(s) para outro fim, designadamente comercial, carece de autorização do respetivo autor ou editor da obra.

Na medida em que todas as obras da UC Digitalis se encontram protegidas pelo Código do Direito de Autor e Direitos Conexos e demais legislação aplicável, toda a cópia, parcial ou total, deste documento, nos casos em que é legalmente admitida, deverá conter ou fazer-se acompanhar por este aviso.

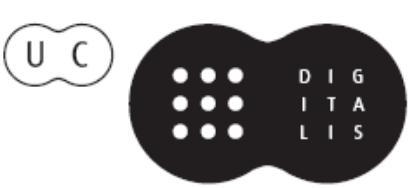


Ana Leonar Pereira Jםão Rui Pita [ Coordenaçä̃ ]

\section{Miguel Bomberda e as singularidades de uma época}

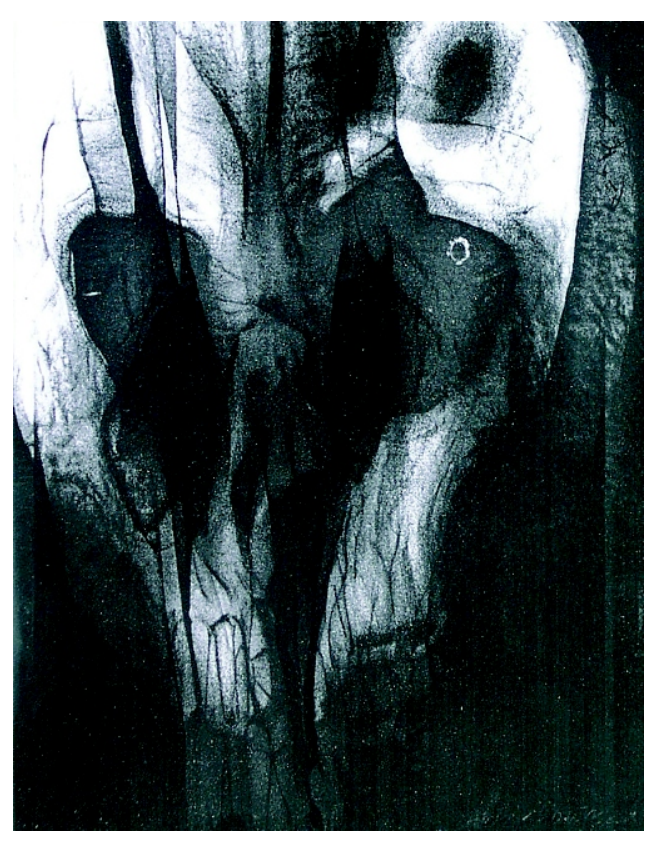


(Página deixada propositadamente em branco) 
Ana Leonor Pereira

João Rui Pita

(Coordenação)

\title{
FOLHA DE ROSTO
}

\author{
Miguel Bombarda (1851-1910)
}

a as singularidades de uma época 


\section{Coordenação Científica da Colecção Ciências e Culturas}

João Rui Pita e Ana Leonor Pereira

Os originais enviados são sujeitos a apreciação científica por referees

\section{Coordenação Editorial}

Maria João Padez Ferreira de Castro

\section{Edição}

Imprensa da Universidade de Coimbra

Email: impresauc@ci.uc.pt

URL: http://www.imp.uc.pt • Normas de publicação de colecções

Design

António Barros

Pré-Impressão

António Resende

Imprensa da Universidade de Coimbra

Capa

António Dantas. Sem título, 2002. Col. António Barros. Coimbra

Impressão e Acabamento

SerSilito • Maia

\section{ISBN}

978-989-8074-11-9

\section{Depósito Legal}

Obra publicada com a colaboração de:
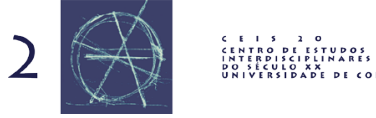

Obra publicada com o apoio de:

FCT Fundação para a Ciência e a Tecnologia

MINISTÉRIO DA CIÊNCIA, TECNOLOGIA E ENSINO SUPERIOR Portugal

Programa Operacional Ciência, Tecnologia, Inovação do Quadro Comunitário de Apoio III

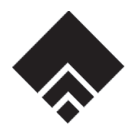

Fundaçāo Eng. António de Almeida

(C) Agosto 2006, Imprensa da Universidade de Coimbra 


\author{
Alexandre Manuel Teixeira Guedes da Silva Oliveira \\ Doutorando em Ciências Sociais, FCSH-UNL, Lisboa, Portugal
}

\title{
A INFLUÊNCIA DA ANTROPOSOCIOLOGIA E CRIMINALÍ́stica NA FORMAÇĀo INTELECTUAL DE MENDES CORREIA
}

A formação intelectual do Prof. Mendes Corrêa ${ }^{1}$, inseriu-se dentro de um espírito muito peculiar vivido nos finais do século XIX até ao primeiro quartel do século XX, no qual a Academia Politécnica do Porto, se notabilizou pelo dinamismo político e social dos seus alunos, no qual a ciência era encarada como aludiu Mendes Corrêa, de oráculo da vida e lama onde "o homem reduzia-se a um complexo físico-químico explicável por tactismos e tropismos pela termodinâmica e pela electricidade ${ }^{2}$ ».

Consideremos a este respeito que as palavras do académico portuense, de modo algum são elevadas, porquanto entre os seus colegas de graduação se contavam entre outros, Abel Salazar, Afonso Veríssimo Zúquete, Analecto Domingos Santos, António da Costa Portela, Adriano Rodrigues, Carlos Faria Ramalhão, Leonardo Coimbra,

1 António Augusto Esteves Mendes Corrêa, nasceu na cidade do Porto a 4 de Abril de 1888. Filho de António Maria Esteves Mendes Côrrea, médico e vereador da Câmara Municipal do Porto, e de Etelvina Mendes Corrêa. Concluiu o Curso Preparatório de Medicina na Academia Politécnica do Porto e o Curso de Medicina na Escola Médico-Cirúrgica da mesma cidade, obtendo a classificação final de 19 valores, apresentado uma dissertação subordinada ao tema $O$ Génio e o Talento na Patologia.

A sua carreira clínica foi breve, porquanto no mesmo ano da sua formatura, foi nomeado assistente de Ciências Biológicas na recém criada Faculdade de Ciências da Universidade do Porto. O fascínio pela Psiquiatria e Antropologia Criminal, levaram-no no ano seguinte a exercer a docência da cadeira de Antropologia, desempenhando também as funções de juiz-adjunto e médico-antropologista na antiga Tutoria Central da Infância do Porto.

O ano de 1913, ficou marcado pelas suas provas públicas na FCUP, apresentando uma dissertação intitulada Os Criminosos Portugueses, estudos de Antropologia Criminal.

Em 1919, foi nomeado professor ordinário de Geografia e Etnologia na efémera Faculdade de Letras do Porto. Dois anos volvidos, obteve cátedra na FCUP. Entre os anos de 1936 a 1942, foi presidente da Câmara Municipal do Porto, intervindo igualmente nos alicerces da política do Estado Novo, como deputado a partir de 1945 à Assembleia Nacional.

Todavia da sua vasta obra académica, desenvolvida até 1960, destaca-se a sua acção na Sociedade Portuguesa de Antropologia e Etnologia, através da criação do Museu de Antropologia, e da revista de Trabalhos de Antropologia e Etnologia (ainda hoje em publicação), e o seu contributo na organização do $1 .{ }^{\circ}$ Congresso Nacional de Antropologia Colonial. Mendes Corrêa faleceu em Lisboa a 7 de Janeiro de 1960.

${ }^{2}$ Mendes Corrêa, Em face de Deus, Porto, 1946, pp. 40-43. 
Mário Cambezes, Hernâni Monteiro e Victor da Cunha Ramos, que se impuseram intelectualmente nas letras e ciências a partir da segunda década de vinte.

Desta ebulição intelectual, consideremos a título de exemplo a tradição dos estudos antropológicos, nas inúmeras dissertações realizadas pelos alunos da antiga Escola Médico-Cirúrgica, até à criação em 1911, da disciplina de Antropologia na Faculdade de Ciências da Universidade do Porto, bem como a fundação em 1918, da Sociedade Portuguesa de Antropologia e Etnologia.

Neste renovado sopro mental escreveu Mendes Corrêa, em Raça e Nacionalidade (1919), a convicção que tinha na Antroposociologia, como ciência integral para a compreensão e desenvolvimento dos povos. Regista o autor, quando se referiu à crise da Antroposociologia a partir dos finais do século XIX, num tom vaticinador, contra o excessivo uso por parte dos pangermanistas na utilização das suas teses para fins dúbios e rácicos, baseados nas concepçōes do conde A. de Gobineau (1816-1882), na defesa da desigualdade das raças, através de valores psicossociais arianos, como analogia desigualdades com outros povos, sobretudo na identidade dos seus estados mentais e celebrais ${ }^{3}$.

De facto a doutrina preconizada por A. de Gobineau, tinha como elo especulativo de que as diferentes raças humanas eram por constituição inatas e desiguais no seu valor e capacidade para absorver e criarem cultura; só modificando o seu carácter inicial por cruzamento com outras estirpes. Neste contexto o génio de uma raça, dependia pouco das condiçôes de clima, factores ambientais, épocas e por isso era absurdo pensar que todos os homens seriam capazes de igual grau de perfeição, defendo assim que as raças brancas de criadoras de cultura, mas que estavam actualmente desvirtuadas, devido às misturas raciais.

Estas concepções de alguma forma seriam reforçada mais tarde por C. Darwin, através da teoria da selecção natural aplicada à espécie humana, e que Paul Topinard ${ }^{4}$ (L'Anthropologie, 1876) e A. de Quatrefages (L'Espèce Humaine, 1877)5 , utilizaram tais contributos para descrição e de classificação das raças humanas, e de igual modo Broca $^{6}$, com a lei de selecção social para explicação de todos os fenómenos sociais e inter-sociais ${ }^{7}$, presentes no tratado Instructions Craniologiques et Cramioométriques de la Societé d'Anthropologie de Paris (1875). Estas ilações levaram Mendes Corrêa à convicção de que o critério da superioridade rácica era em si mesmo excessiva, restrita e elitista. Efectivamente, em sua opiniāo, tais confusões levariam mais cedo ou mais tarde à perda do conceito de império alemão, afirmando:

\footnotetext{
${ }^{3}$ Veja-se a propósito as teorias em Essai sur l'Inégalité des Races Humaines (1853), rejeitando toda a influência do meio sobre o homem nas deferentes etnias que se produzem no decurso da história, única base de explicação dos progressos, das decadências e estagnações apresentadas pelas sociedades humanas.

${ }^{4}$ Salientamos a título de curiosidade que Topinard, foi o autor do neologismo criminologia, embora algum tempo depois o psiquiatra Garófalo, publica-se um ensaio com o mesmo título.

${ }^{5}$ Embora estes autores associassem aspectos sociais e culturais da história nas suas investigações.

${ }^{6}$ Igualmente Broca elaborou estudos forenses designadamente no âmbito da Psiquiatria.

${ }^{7}$ Refira-se ainda os contributos de Ammou, Muffang ou Livi, que procuraram através da Antropometria e a Estatística, estabelecerem leis científicas à Antroposociologia.
} 
«Uma desastrada confusão se estabeleceu entre Antroposociologia e pangermanismo, e dessa confusão provém em grande parte o desfavor com que até nos meios mais cultos déla se fala. Como todos os grandes impérios da história, o império alemão ha de desaparecer mais cedo ou mais tarde na voragem exterminadora das maiores ambições humanas, e a antroposociologia ficará de pé, porque como sciência biosociológica éla mesma proclama a evolução dos povos e a instabilidade das organisações sociaes, mesmo das mais fortes e menos sujeitas a influências dissolventes e abastardantes ${ }^{8}$ ”.

Deste modo, Mendes Corrêa distanciava-se do pangermanismo, numa altura em que imperava em Portugal a corrente germanófila que contrariou, pouco tempo antes, a intervenção militar portuguesa ao lado dos Aliados, e que viveu de forma dramática o assassinato a 14 de Dezembro de 1918, de Sidónio Pais. O lente portuense empregou assim em Raça e Nacionalidade uma afirmação de Friedrich Ratzel, para superar lacunas e influências ambíguas, onde o geógrafo alemão vaticinava que os problemas relativos à história e etnicidade seriam difíceis de solucionar, porquanto se afastavam: "uma pretendida diferença essencial do que chamam raças», decifrando o termo raça desta forma: «Mas o que é a propria raça, senão o producto dos meios anteriores multiplicando-se infinitamente durante todo o período que decorreu desde a aparição [...] do género humano?"».

Sentimos portanto que as teses de Ratzel influenciaram em parte as investigações de Mendes Côrrea, no primeiro quartel do século XX, onde a "Anthropogeographie» estava directamente ligada às ciências sociais (sobretudo à geografia, antropologia e arqueologia), cujo exemplo mais eficaz se encontra num dos seus ensaios Os Povos Primitivos da Lusitânia (1924), onde nas primeiras páginas dedica um significativo capítulo à posição geográfica portuguesa a que chamou de "o velho solar lusitano", especificando a sua individualização no âmbito da geografia física e humana.

Para Mendes Corrêa, o seu rompimento com a geografia descritiva, enquanto professor da mesma na Faculdade de Letras da UP (que tê-la-á considerado fastidiosa), substituindo-a pela Geomorfologia, que na sua opinião, fornecia uma imagem mais profunda da realidade, como acentuou nas suas palavras: «inundou de intensa luz a história do globo e deu vida às formas terrestres, que á nossa existência efémera apareciam anteriormente como intransformaveis, mudas e eternas ${ }^{10} »$. Nesta linha, os seus estudos, orientaram-se num encadeamento evolutivo na definição de um quadro cronológico das culturas Ibéricas, e a delimitação das áreas de influências geográficas que veriam a influenciar posteriormente os seus estudos em Arqueologia.

De facto Ratzel considerava o mundo uno, sendo por isso percorrido em todos os sentidos pela humanidade, em deslocações lentas ou rápidas estabelecendo assim estagnações ou desenvolvimentos da cultura. Para o geógrafo alemão, o conceito de tempo e espaço eram de papel de vital importância para a compreensão da história e

${ }^{8}$ A. A. Mendes Corrêa, Raça e Nacionalidade, Porto, 1919, p. 13.

${ }^{9}$ Idem, op. Cit., p. 18

${ }^{10}$ A. A. Mendes Côrrea, Os Povos Primitivos da Lusitânia, Geografia, Arqueologia, Antropologia, 2 milhar, Porto, 1924, p. 5. 
que Paul Mercier sintetiza desta forma: «a invenção, em definitivo, é rara, a transmissão e a disseminação são mais frequentes ${ }^{11}$.

Mendes Côrrea introduziu assim uma Antroposociologia, que podemos classificar como ciência que estabelece conexões entre o ser físico e as maneiras de pensar perante uma dada acção, e na forma de revolver ou ultrapassar os problemas epistemológicos, ou um ramo de saber que estuda os traços unitivos entre o homem animal e vegetativo, e o homem social, expressando contudo, ser ainda uma disciplina em embrião. Desta maneira a Antroposociologia, propunha-se abranger uma certa interdisciplinariedade ao estudar a psicologia das raças, a partir dos problemas demográficos, económicos, políticos para explicar o presente, mas sobretudo o passado, designadamente a origem e o desaparecimento das civilizações.

Lentamente, Mendes Côrrea abandonaria uma ciência virada para o estudo do homem natural, onde o Positivismo e Historicismo foram os cânones fundamentais durante o século XIX, em troca de uma nova ciência, emergente para as questóes sociais do homem, ou seja, o cientista portuense acompanhou a trajectória dos seus colegas europeus na crise do positivismo, na crescente preocupação com a história e a etnicidade dos grupos humanos e culturais. A partir desta perspectiva, e através do estudo psicossocial das raças, encontrava-se longe das doutrinas baseadas nos caracteres antropológicos ou anatómicos (a estatura, a cor dos olhos, dos cabelos, da pele, etc.), embora anos antes, tivesse centrado as suas investigações dentro de uma Antropologia Forense e Criminalística de inspiração frenologista.

Embora a teoria das localizações seja insustentável ao seu pensamento, não é menos certo que Mendes Corrêa tivesse em atenção os seus subsídios para as bases de uma Psicologia e Psiquiatria modernas, porquanto como salienta o Prof. Pinto da Costa: «se aceitássemos que seria possível, pelo estudo do crânio, conhecer as tendências das pessoas, também poderia ser possível, por uma educação adequada, evitar as consequências negativas de tais tendências ${ }^{12}$ ». Assim, o lente portuense estabeleceu a dualidade das características anatómicas e criminais, que é bem demonstrativo a seguinte frase: «É de crer que haja correlações entre alguns sinaes anatómicos e as tendências criminaes mas essas correlações ainda não encontraram uma regra que as definisse $\mathrm{e}^{13}$.

Convém salientar que no virar do século XIX, os estudos de Antropologia Criminal na cidade do Porto floresceram rapidamente. Em 1880, o Prof. Roberto Frias, apresentou como tese de doutoramento à Escola Médico-Cirúrgica, O Crime, apontamentos para a sistematização da criminalidade, e no dizer de Luís de Pina tratou-se do primeiro impulso na bibliografia nacional após o aparecimento do Homo delinquente de Lombroso: «O estudo de Roberto Frias foi publicado, apenas, quatro anos depois dêste ${ }^{14}$. Logo em 1885, foi aberto também na cidade do Porto, pela mão do

\footnotetext{
${ }^{11}$ Paul Mercier, Histoire de l'Anthropologie, Paris, 1966, p. 56.

12 José Pinto da Costa, «Psicopatologia Criminal», in Psiquiatria e Psicologia Forenses, (texto policopiado), Porto, 2000, p. 27.

${ }^{13}$ A. A. Mendes Corrêa, Os Criminosos Portugueses, Porto, 1913, p. 114.

${ }^{14}$ Luís de Pina, "A Antropologia Criminal em Portugal, síntese histórica» in Congresso do Mundo Português, Lisboa, 1940, p. 687.
} 
Prof. Luís Viegas, um Laboratório de Antropologia no Hospital Conde de Ferreira, na tentativa de impor o ensino oficial da Antropologia Criminal. Em 1902, A. Ferreira Augusto criou o Posto "Anthropométrico», junto ao edifício do Tribunal da Relação, e publicou a primeira revista da especialidade Postos Anthropométricos, de curta existência ${ }^{15}$, embora "notícias várias" deixem antever a existência de diversas tentativas de instalação de serviços antropométricos anteriores na cidade Lisboa (nomeadamente na Penitenciária e no Limoeiro) ${ }^{16}$, e mesmo no Porto em 1893, através dos esforços do «Comissário Terra Viana, coadjuvado por Eduardo Maia no tempo quintanista de Medicina ${ }^{17}$ ». Desta forma a contribuição da Escola Médico-Cirúrgica foi basilar para a projecção da Antropologia Criminal.

Como já salientamos anteriormente, o Prof. Mendes Corrêa encontrava-se afastado das teorias frenológicas, em especial do criminologista italiano Cesare Lombroso ${ }^{18}$ (1836-1909), professor de medicina legal, em Turim, que defendia que os criminosos eram inatos e não criados, e por isso mesmo podiam ser distinguidos das pessoas normais pela forma dos seus crânios. Neste direccionamento, devemos ter em conta que durante o século XIX os investigadores criminais tentaram encontrar uma descrição biológica para explicar os comportamentos desviantes extremos, em especial dos psicopatas, sendo aceite a posição frenológica, sem muitos obstáculos, embora nunca fosse comprovada, acabando por ser desacreditada, pelas crueldades inferidas a alguns dos seus doentes, conquanto os esforços tivessem como base a unidade psicossomática que exigia uma análise a mais exaustiva possível para se obter um diagnóstico da psicogénese delitiva ${ }^{19}$.

Actualmente, as teses que defendem uma origem biológica para os comportamentos desviantes dividem-se em dois campos; a do português António Damásio, que põe em destaque o papel do córtex orbitofrontal, como área sensível nos psicopatas, e a teoria de James Blair, que defende que a amígdala (uma pequena área entre o córtex orbitofrontal e o hipocampo) encerra os comportamentos dos criminosos ${ }^{20}$.

${ }^{15}$ Vd. Alberto Xavier da Cunha, "A Antropologia Física em Portugal, até aos fins do século XIX", in História e Desenvolvimento da Ciência em Portugal, vol. II, Lisboa, MCMLXXXVI, p. 1019. Convém referir os contributos nos finais do século XIX, para a implantação da Antropologia Criminal em Portugal, por parte de alguns médicos e juristas, entre eles, Júlio de Matos, Miguel Bombarda, António Maria de Sena, Basílio Freire, Ferraz de Macedo, Roberto Frias, Alfredo Luiz Lopes, Ferreira Augusto; Ferreira Deusdado.

${ }^{16}$ Ferreira Augusto, Assistência judiciária, Serviços médico legais, Alienados criminosos. Notariado, Porto, 1900 , p. 365.

${ }^{17}$ Alberto Pessoa, «História da Introdução em Portugal dos Métodos Científicos de Identificação Criminal», in Congresso do Mundo Português, Lisboa, 1940, p. 716

${ }^{18}$ Lombroso, desenvolveu a sua teoria sobre a imperfeição do indivíduo, ao estudar em 1870, a fosseta occipital mediana, no crânio de Vilela.

${ }^{19}$ A psicogénese delitiva, compreende os mecanismos psicológicos da conduta do delinquente e a natureza psíquica do acto e estado do indivíduo no momento de delinquência. A psicogénese delitiva apreciada num ângulo psiquiátrico pode ser encarada de dois modos diferentes. Estudando o autor do facto e depois de diagnosticar o seu estado mental estabelecer a eventual relação deste com o acto cometido, ou partindo das características do crime, deduzindo o síndrome mental que lhe deu origem.

${ }^{20} \mathrm{Vd}$., sobre estes assuntos, José Pinto da Costa, Psiquiatria e Psicologia Forenses, Porto, 2000 e Custódio Rodrigues et al., Motivação, Porto, 1998. 
Houve por conseguinte em Mendes Corrêa, a caracterização de uma dualidade entre o génio humano e a questão da delinquência, encarando a Criminologia, como primacial, na definição da personalidade bio-psico-moral, centrando na pesquisa do funcionamento cerebral dos fenómenos da vida mental e colectiva, que resultavam sem dúvida, do funcionamento dos sistemas nervosos individuais ${ }^{21}$. A este propósito Rui de Pina considera que os esforços efectuados pelo lente portuense se insurgiram contra os exageros cometidos pela escola lombrosiana ${ }^{22}$.

E de facto o Prof. Mendes Corrêa, separou as águas ao afirmar a meio dos anos vinte, a existência de duas escolas de Antropologia Criminal, de um lado a Escola Italiana baseada em Lombroso, e uma outra de várias orientaçôes doutrinárias e adversa: à concepção lombrosiana do delinquente e do delito ${ }^{23}$ ", conquanto realce o esforço necessário para irradiar a teoria lombrosiana da comunidade científica. Contudo, salienta haver homens com maior predisposição para a criminalidade do que outros, embora refute a existência de um tipo de delinquente nato, pois todos podem ser delinquentes; embora uns com uma maior intensidade do que outros: "necessariamente pela estigmatisação sôbre a qual LOMBROSO erigiu uma extranha raça de criminosos ${ }^{24}$ ".

Contudo o lente portuense via na tese lombrosiana o mérito inegável ao pôr em foco, a personalidade do delinquente que até então era substituída na graduação da pena, (exclusivamente pela gravidade do delito), chamando atenção: "para estigmas que eram despresados mas de que a seu turno exagerou a significação e a importância ${ }^{25}$ ". Neste sentido para Mendes Corrêa, na Antropologia Criminal Integral, não existia uma ligação directa à Patologia, embora admiti-se uma patologia dos delinquentes.

Contudo, esta mesma, encontrava suporte nas suas pesquisas, de certo modo devido à influência marcante nas teses defendidas pelo criminologista espanhol Quintiliano Saldanã que observava não ser a intenção criminosa o principal do delito, mas acima de tudo a capacidade criminal e o resultado quer do crime quer da pena, ou seja, o grau de capacidade criminal do autor, e a eficácia da pena a aplicar. Neste propósito, Mendes Corrêa defendia que a Antropologia Criminal: "não deve considerar sistemáticamente o criminoso como um ser bio-antropológicamente aberrante, mas deve encara-lo também como um homem normal ${ }^{26}$ ».

Neste ponto de vista, o antropólogo portuense encarava a criminalidade, associada aos factores económicos, sociais e mormente morais, dando enfoque às condições educativas, higiene física e saúde mental. Tais consideraçôes, deviam-se às suas investigaçôes efectuadas em diversas cadeias portuguesas e no refúgio da Tutoria da Infância do Porto ao longo uma década. Lembremos que a sua tese de concurso para a

\footnotetext{
${ }^{21}$ A. A. Mendes Corrêa, Raça e Nacionalidade, p. 17.

${ }^{22}$ Luís de Pina, "A Antropologia Criminal em Portugal, síntese histórica" in Congresso do Mundo Português, vol. XII, Lisboa, 1940, p. 697.

${ }^{23}$ A. A. Mendes Corrêa, "Antropologia Criminal Integral, o normal delinquente e a crise moral», Sep. do Boletim do Instituto de Criminologia, Lisboa, 1925, p. 1.

${ }^{24}$ Idem, Ibidem, p. 2.

25 Idem, Ibidem, p. 22.

${ }^{26}$ Idem, Ibidem, p. 8.
} 
Faculdade de Ciências do Porto, se inseriu na vertente Criminalística (Os Criminosos portugueses,... impressa em 1914), defendida em 1913, e entre 1915 a 1919, publicou notáveis trabalhos entre os quais Crianças delinquentes, subsídios para o estudo da criminalidade infantil em Portugal e Mendigos e criminosos: Vejamos como o autor refere ao seu trabalho de campo: «deparei com uma grande massa de delinquentes cujos actos delituosos não podiam ser considerados o produto de taras degenerativas ou defeitos patológicos, mas essencialmente a consequência dum lastimavel regimen educativo anterior ${ }^{27}$ ".

$\mathrm{Na}$ concepção atrás formulada, estava presente a delinquência como fruto de uma evolução de trajecto de mal-estar psicossocial, que em diversos casos o início da criminalidade que começava a manifestar a partir da infância, propondo por isso um estudo sistemático e criterioso a ter com estas crianças: «Relativamente aos menores delinquentes, a individualização da pena requer naturalmente, além do conhecimento do crime e das circumstancias deste, o estudo da organisação fisica e psiquica do menor e das condições do meio ${ }^{28}$ ». Convém esclarecer que Mendes Corrêa, restabeleceu os estudos sobre a infância delinquente, já antes iniciados por Ferreira Augusto e Luiz Viegas, a partir de 1908. Desta forma Luís de Pina salientou que o sistema criminológico aplicado às crianças delinquentes, «embora lentamente», levou à influência da Antropologia Criminal, baseada: «sobretudo na apreciação do valor da personalidade morfo-psico-moral dos indivíduos ${ }^{29}$ ".

Nesta orientação, estava a sua preocupação de estabelecer uma metodologia o mais científica possível, relativamente aos exames médico-antropológicos, que como sublinha requererem além da preparação científica e técnica que todos os médicos devem possuir, alguns conhecimentos de antropologia geral, psicologia experimental e pedagogia, que se encontravam fora das competências médicas. Por isso a especial atenção que requeria a interpretação dos resultados obtidos ${ }^{30}$. Nestas considerações estavam sobretudo focadas que as competências do médico não estavam em julgar o delinquente, mas sim, descrever os factos, numa perspectiva mais científica possível, de modo a proporcionar um julgamento verídico do sucedido.

Porém em Mendes Corrêa, encontrasse implícito a defesa da sociedade que tinha ser encarada dentro de uma dualidade de critérios, a abstracção e a realidade. A primeira de suporte jurídico e a segunda como homem social: «Em Portugal com lá fora, a criminalidade não diminue com a instrução. Esta traz apenas um descrescimo no número dos crimes audaciosos, violentos e crueis, compensado por um aumento no dos hábeis e astuciosos ${ }^{31}$. Como se vê, as preocupaçôes sociais com a criminalidade não se reduziram ao binómio Subjectivo/Objectivo ou Consciência/Exterior, perante a sociedade, igualmente defendeu medidas de combate à miséria, com intuitos profi-

${ }^{27}$ Idem, Ibidem, p. 3.

${ }^{28}$ A. A. Mendes Corrêa, Creanças delinquentes, subsidios para o estudo da criminalidade infantil em Portugal, Coimbra, 1915, pp. 110-111.

${ }^{29}$ Luís de Pina, op. cit., p. 705.

${ }^{30}$ Cfr. A. A. Mendes Corrêa, Creanças delinquentes..,. pp. 118-128.

${ }^{31}$ A. A. Mendes Corrêa, «Instrucção e Criminalidade em Portugal», Sep. do Porto Médico (2.a série, n. $\left.{ }^{\circ} 1\right)$, Porto, 1912 , p. 7. 
láticos de combate à delinquência, dado que: «assim como a individualisação da pena se impõe para os criminosos, assim para os mendigos se impõe a individualisação da assistência. A esmola nas ruas favorece e estima o crime ${ }^{32}$ ». Nesta correlação se encontram subentendidos que tanto a agressividade e violência, estão relacionados com a fome, a sede, a cólera e a alegria.

Mas ao contrário da caridade individualizada e a prestada pelas instituiçôes religiosas aos internatos, asilos, hospitais, Mendes Corrêa, estabeleceu a necessidade de uma assistência domiciliária, baseada no conhecimento prévio do miserável: «exercido por meio de visitadores idóneos, e constando de dádivas em géneros, vestuário ou dinheiro, consoante a personalidade e necessidades do beneficiado ${ }^{33}$. Só assim seria possível a compreensão da delinquência, através do estudo da personalidade do indivíduo no seu ambiente vivencial, da aprendizagem escolar, na educação moral e religiosa, da capacidade económica familiar e na sua interacção social. Portanto, a análise de Mendes Corrêa, passava por um esclarecimento de cada caso e sua natureza concreta de apoio social a prestar, para obviar irregularidades possíveis parante o subsidiado, afirmando a este respeito: "Assim como muitos delinquentes são conduzidos a partir do crime por anomalias francamente patológicas, assim também é a fatalidade da doença ou da invalidez física ou mental que determina muitos individuos, desajudados de assistência familiar e de assistência publica, a estender as mãos á caridade dos transeuntes ${ }^{34_{»}}$.

Foi contudo na alegação de existência de uma «Nova Antropologia Criminal», que Mendes Corrêa, veria fomentar quezílias com alguns reputados criminalistas europeus que defendiam as teses Lombroso. Assim na abertura do ensaio A nova e a velha Anthropologia Criminal, o autor reconheceu nunca esperar que o seu artigo intitulado de «Nova Antropologia Criminal», levanta-se tanta irritabilidade por parte de alguns investigadores forenses ao definir a existência de uma nova Criminologia, porquanto não passava de «uma contribuição importante para sua renovação ${ }^{35}$ », ilustrando que esse qualificativo não significava uma disciplina diferente com o propósito de demonstrar a existência biologismo, patologismo e sociologismo, que nas suas palavras: «havia sido modificador ou até abandonadas, sob influência dum ambiente mais calmo e prudente e de elementos novos fornecidos por disciplinas connexas ou subsidiarias ${ }^{36}$ ».

Desta forma as teses defendidas por Mendes Corrêa, foram alvo de discussão em especial pelo Prof. Carrara, sogro de Lombroso e continuador da cátedra em Turim. Objectava o criminologista italiano, da expressão sugerida por Mendes Corrêa de «delinquente normal» de pouco feliz. Contudo o antropólogo portuense na sua réplica, defendia que a palavra «normal» figurava como substantivo e «delinquente» como adjectivo significativo ao qual traduzia como expressão o indivíduo biologicamente e psicologicamente normal que praticou o crime: «são os 'pseudo-delinquentes', dizem Carrara e os seus confrades lombrosianos. Mas quem pratica delictos, não é 'delin-

32 A. A. Mendes Corrêa, "Mendigos e Criminosos" Sep. do Portugal Médico (3. ${ }^{\circ}$ série - vol. V, n. 1 - 1919), Porto, 1919, p. 8.

${ }^{33}$ Idem, Ibidem, p. 8.

${ }^{34}$ Idem, Ibidem, p. 3.

${ }^{35}$ A. A. Mendes Corrêa, A nova e a velha Anthropologia Criminal, Rio de Janeiro, 1937, p. 3.

36 Idem, Ibidem. 
quente'? Nenhum diccionario, nenhum codigo, nenhum magistrado - escrevemos então - definirá doutra maneira a palavra 'delinquente' ${ }^{37}$ ».

Tais intransigências levaram Carrara, afirmar de nada de original encontrava nas bases da nova Antropologia Criminal, porque era propriamente Antropologia Criminal de Lombroso, que estava presente, e se apresentava apenas a Psicologia individual dos delinquentes, está tinha raízes muito mais antigas, o que levou Mendes Corrêa a responder que o seu ensaio não tratava apenas de psicologia individual dos delinquentes, «mas sobretudo psychologia individual dos delinquentes» ligada aos aspectos psico-morais. que: "A velha escola de psychologia criminal a que alludia Carrara e que vem do seculo XVIII, não é a moderna psychologia individual, servida pelos methodos de que hoje se dispõe e illuminada por orientações novas, como as que surgiram na psychiatria, na psychologia experimental, etc ${ }^{38}$.

Mas as divisões do académico não só se estenderam a Carrara, igualmente o Prof. Gaetano Boschi, membro da Sociedade Italiana de Antropologia e Psicologia de Ferrara, levaram a tecer observaçôes sobre a Nova Antropologia Criminal e Antropologia Criminal Integral, defendida por Saldanã, e designadamente por Benigno Di Tullio, professor de Antropologia Criminal da Universidade de Roma, e ao qual Mendes Corrêa, reconhecia autoridade científica, ao confirmar as suas investigaçóes em muitos milhares delinquentes.

O pensamento Di Tullio, manifestava-se que a Nova Antropologia Criminal, não tinha trazido à «velha» Antropologia Criminal, contributos inovadores, definindo por isso a Antropologia Criminal como uma ciência originariamente italiana bem como as suas disciplinas auxiliares. Contudo considerou que a mesma tinha evoluído perante as novas técnicas de investigação. Neste sentido, considerava que os trabalhos desenvolvidos por Saldanã eram importantes, sobretudo nas suas conclusões.

Perante tais factos a Nova Antropologia Criminal, tendia novos critérios de «individualização" na definição dos caracteres «sobretudo moraes, de cada individuo" e em contraste com a escola lombrosiana, visava apenas a inclusão de cada delinquente num compartimento de classificação como refere Mendes Corrêa: «Decerto as classificações têm um valor auxiliar, mas raro são os casos de criminalidade reductiveis á simplicidade eschematica do tipo ${ }^{39}{ }$.

Podemos portanto aduzir que o trajecto científico de Mendes Corrêa, teve em conta os aspectos de valorização criminógenos extrínsecos do indivíduo, em todas as fases de desenvolvimento de forma a arquitectar a personalidade criminógena, para o qual o Direito Penal da sua época, era em mero elemento do processo delitivo, uma espécie de objecto secundário e quase marginal a não ser para receber a pena. Como denota o Prof. Pinto da Costa: «era assim que o Direito Penal, numa perspectiva antropológica criminal e patológica preferia os doentes psíquicos ${ }^{40}$ ». Nesta sensatez o antropólogo portuense tinha como objectivo o conhecimento profundo do delinquente, no sentido da sua personalidade biológica, no qual possibilitava antever como essa personalidade

\footnotetext{
${ }^{37}$ Idem, Ibidem, p. 5.

${ }^{38}$ Idem. Ibidem.

${ }^{39}$ Idem., Ibidem, p. 68.

${ }^{40}$ José Pinto da Costa, «Delinquência dos Doentes Mentais», op. cit., p. 149.
} 
agiria em determinadas circunstâncias, perante certos estímulos intrínsecos e extrínsecos, ou seja nos métodos presentemente aplicados em Criminologia.

\section{Bibliografia CitAdA}

Augusto, Ferreira, 1900, Assistência judiciária, Serviços médico legais, Alienados criminosos. Notariado, Porto.

CorrêA, A. A. Mendes, 1912, «Instrucção e Criminalidade em Portugal», Sep. do Porto Médico (2.a série, n. $\left.{ }^{\circ} 1\right)$, Porto.

—, 1913, Os Criminosos Portugueses, Porto, Imprensa Portuguesa.

—, 1915, Creanças delinquentes, subsidios para o estudo da criminalidade infantil em Portugal, Coimbra, F. França Amado, Editor.

—, 1919, «Mendigos e Criminosos», Sep. do Portugal Médico (3.º série - vol. V, n. ${ }^{\circ} 1$ - 1919), Porto, Tip. da Enciclopédia Portuguesa.

—, 1919, Raça e Nacionalidade, Porto, Renascença Portuguesa.

—, 1928, «Antropologia Criminal Integral, o normal delinquente e a crise moral», Sep. do Boletim do Instituto de Criminologia, Lisboa, Oficina Gráfica da Cadeia Nacional.

—, 1937, A Nova e a Velha Anthopologia Criminal, Rio de Janeiro, Imprensa Nacional.

—, 1946, Em face de Deus, Porto, Fernando Machado.

CunHA, Alberto Xavier da, 1976, "A Antropologia Física em Portugal, até aos fins do século XIX», in História e Desenvolvimento da Ciência em Portugal, Lisboa, vol. II.

Mercier, Paul, 1966, Histoire de l'Anthropologie, Paris, Presses Universitaires de France.

PESSOA, Alberto, 1940, «História da Introdução em Portugal dos Métodos Científicos de Identificação Criminal», in Congresso do Mundo Português, Lisboa, vol. XII.

PINA, Luís de, 1940, «A Antropologia Criminal em Portugal, síntese histórica» in Congresso do Mundo Português, Lisboa, vol. XII.

Pinto Da Costa, José, 2000, Psiquiatria e Psicologia Forenses, Instituto de Medicina Legal do Porto, texto policopiado, Porto.

Rodrigues, Custódio, 1998, Motivação, Porto, Ediçōes Contraponto.

Resumo - A presente comunicação tem como finalidade analisar a influência da Antroposociologia e Criminalística na carreira inicial do Professor Mendes Correia.

Desta forma a formação intelectual do lente portuense, inseriu-se dentro de um espírito muito peculiar, vivido nos finais do século XIX até ao primeiro quartel do século XX, no qual a Academia Politécnica do Porto foi um alfobre de efervescência de novas ideias políticas e sociais preconizadas pelos seus estudantes, no qual a ciência e o modelo transformista foram encarados como referiu o autor (anos mais tarde), de oráculo do problema da vida e da lama, no qual o bisturi reduzia o homem a um: «complexo físico-químico explicável por tactismos e tropismos pela termodinâmica e pela electricida».

Abstract - The lecture aims at analysing the influence of Anthroposociology and Criminal Law in the early career of Professor Mendes Correia.

The intellectual education of this Professor from Oporto was built within the frame of a very peculiar spirit that was felt in the end of the nineteenth century and first quarter of the twentieth century. During this period, the Polytechnic Academy of Oporto was the ground where new political and social ideas germinated and were proclaimed by the students; where science and the transformist model were seen as the oracle for the problems of life as the author stated (some years later); where the scalpel reduced man to a 'physicochemical complex, explained through tactism and tropism by thermodynamics and electricity'. 
(Página deixada propositadamente em branco) 


\section{Colecção \\ Ciências e Culturas \\ Cuimbra 2006}

